\title{
sciendo
}

\section{Effects of the Pitch Surface on Displacement of Youth Players During Soccer Match-Play}

\author{
by \\ Ângelo Brito ${ }^{1}$, Paulo Roriz², Pedro Silva ${ }^{1}$, Ricardo Duarte ${ }^{3}$, Júlio Garganta ${ }^{1}$
}

The aim of this study was to analyze the effect of different pitch surfaces (artificial turf, natural turf and dirt field) on positioning and displacement of young soccer players (age: $13.4 \pm 0.5 \mathrm{yrs}$; body height: $161.82 \pm 7.52 \mathrm{~cm}$; body mass: $50.79 \pm 7.22 \mathrm{~kg}$ and playing experience: $3.5 \pm 1.4 \mathrm{yrs}$ ). Data were collected using GPS units which allowed to calculate spatial distribution variability, assessed by measuring entropy of individual distribution maps (ShannEn). Ellipsoidal areas (m2) representing players' displacement on the pitch, centred on the average players' positional coordinates, were also calculated, with axes corresponding to the standard deviations of the displacement in the longitudinal and lateral directions. Analysis of variance (ANOVA) was used to evaluate differences between pitch surfaces and across players' positions. There was significant effect in positioning $(\eta 2=0.146 ; p<0.001)$ and displacement $(\eta 2=0.063 ; p<0.05)$ by the players between pitch surfaces. A dirt field condition induced an increase in the players' movement variability, while players' displacement was more restricted when playing on artificial turf. Also, there were significant effects on positioning ( $\eta 2=0.496 ; p<0.001)$ and displacement $(\eta 2=0.339 ; p<0.001)$ across players' positions. Central midfielders presented the greatest movement variability and displacement while fullbacks showed the lowest variability. Subsequently, the results may contribute to implement strategies that optimise players' performance in different surface conditions.

Key words: movement variability; spatial distribution maps; performance analysis; entropy; tactical demands.

\section{Introduction}

Youth soccer matches are played on natural and artificial turf surfaces. However, in certain regions of Africa and southern Europe many soccer matches are still being played on a dirt field surface. Although we know this reality, there are still many uncertainties concerning the influence of each pitch surface on the tactical demands of young players in match-play.

Soccer players' performance is influenced by tactical, technical, physical and psychological factors (Stølen et al., 2005). More specifically, Impellizzeri and Marcora (2009) suggested that the tactical factor is one of the most important in the analysis of soccer matches. However, since the nature of a soccer match is highly dynamic and complex, assessing players' tactical performance can be a demanding task (Gréhaigne et al., 2011). This is why some researchers suggest that the analysis of variability of players' motion can be seen as an interesting method to identify and classify their performance from a tactical viewpoint (Couceiro et al., 2014). To assess it, a new set of technologies, such as those based on video tracking and global positioning systems (GPS) have contributed to new insights into the analysis of soccer players' performance either in training or during a game (Cummins et al., 2013). Portable GPS devices provide spatial-temporal

\footnotetext{
1 - CIFI2D - Centre for Research, Education, Innovation and Intervention in Sport, Faculty of Sport, University of Porto, Porto, Portugal.

2 - CIDESD-ISMAI, INESC-TEC \& LABIOMEP, Portugal.

3 - CIPER, Faculty of Human Kinetics, SpertLab, University of Lisbon, Cruz Quebrada, Portugal.
} 
data with the reasonable accuracy for tracking players trajectories on the pitch (Coutts and Duffield, 2010; Gray et al., 2010). Positional data are critical to better understand players physical, technical or tactical demands (Cummins et al., 2013; Stølen et al., 2005). Moreover, they also enable to analyse the interactions between player's trajectories, contributing to understanding the intricate motion patterns of players, which are critical in the analysis of tactical performance (Silva et al., 2014a).

Previous studies have demonstrated that analysis of how the players manage the space (Bartlett et al., 2012), measuring the action zone variability, may be a viable method to assess the players tactical performance (Gréhaigne, 2011; Gréhaigne et al., 2001). For instance, Jones and Drust (2007) suggested that if players restricted their action zones to specific pitch zones, this could be interpreted as a more structured game, played according to the players' positions and specific functions. Other studies have suggested that players' spatial distribution variability on the pitch can be a relevant concept to quantify their individual movements from a tactical perspective (Silva et al., 2014a; Silva et al., 2015). For instance, a study conducted by Silva et al. (2014a) concluded that national-level soccer players presented higher variability than regional-level players when playing small-sided games in smaller areas, which may indicate that players of different skills respond in a different manner to the same task constraints. According to the aforementioned authors, greater uncertainty in the players' behavioural modes during smallsided games may be associated with more variable action zones. Thus, it seems relevant to measure the variability to capture and interpret the meaning of situations that occur during soccer matches.

Typical measures of variability from spatial-temporal data include the range, standard deviation or the coefficient of variation, along with central tendency measures (mean, median, and mode). These linear quantities are complemented with more sophisticated analysis, such as the one based on entropy values obtained from player's spatial distribution maps (Couceiro et al., 2014; Silva et al., 2014a; Silva et al., 2015). The entropy, originally described by Shannon (1948), is a non-linear variable that can be used to express the uncertainty of locating the player in a specific region of the soccer pitch (Silva et al., 2014a). Normalized entropy ranges from 0 to 1 , i.e., from highly predicted positions of the players on the pitch to highly variable or unpredicted positions (Silva et al., 2014a). This is why to the authors previously mentioned, entropy can be a valuable tool to quantify players' performance from a tactical perspective.

Players' relative positioning on the pitch, centred on their average positional coordinates, with axes corresponding to the displacement's standard deviations in the longitudinal and lateral directions of the pitch, can also provide additional information on tactical behaviour (Silva et al., 2014b; Yue et al., 2008). In this context, a study by Silva et al. (2014b) analysed the distribution of players' movement coordinates in the longitudinal and lateral pitch directions and confirmed that national-level soccer players displayed differentiated distributions in the longitudinal direction, while regional-level players tended to play on very similar longitudinal coordinates of the pitch, only varying their positioning along the lateral direction. In addition, Yue et al. (2008) concluded that forwards constituted the positional role with the largest range of movements compared with other positions, which means that they have to move in order to provide pass solutions to team mates as well as to escape from the opponent's zone.

Few studies have examined the effect of the pitch surface on players' demands during competitive soccer matches. To date, it has been demonstrated that a pitch surface neither influences tactical performance (Santos et al., 2013), nor the players' movement patterns (Andersson et al., 2008). However, Folgado et al. (2007) showed that the number of successful passes was higher in the natural turf condition compared to the sand surface. In addition, Andersson et al. (2008) showed that ball possession and the number of passes increased $20 \%$ in the artificial turf condition compared to the natural turf.

Despite the importance of these studies, it has not yet been investigated whether the pitch surface influences the positioning and displacement of young soccer players. This information could provide coaches and sports managers with an opportunity to adapt and 
overcome the specific constraints of the pitch surfaces on the tactical profile of the players and respective teams. Moreover, it may maximize the effectiveness of training sessions and implement strategies that could improve players' tactical performance during match-play.

The players and, ultimately the team, are expected to behave in a way that reflects the concept of game designed by coaches. However, the players' intentional actions can be constrained by the effect of the surface where the soccer match is performed. In this context, it is relevant to analyze the player's displacement to adapt and overcome possible constraints imposed by the surface. In this sense, this insight may provide additional information about the specific requirements of each surface and a prerequisite for coaches to improve tactical performance of players and teams, either in training or a game context. Therefore, this study aimed (1) to analyze the displacement variability patterns of players on artificial turf (AT), natural turf (NT) and a dirt field (DF) and; (2) to determine whether there were differences in the spatial distribution variability across players' positions. It was hypothesized that the three pitch conditions would induce differences in positioning and displacement of the players.

\section{Methods}

\section{Participants}

Sixty-six male U-14 soccer players, organized into three teams of twenty-two participated in the study (age: $13.4 \pm 0.5$ years; body height: $161.82 \pm 7.52 \mathrm{~cm}$; body mass: $50.79 \pm$ $7.22 \mathrm{~kg}$ ). Players were selected according to the coach's subjective appraisal of their ability. All players competed at a regional-level exhibiting match and training experience of $3.5 \pm 1.4$ years. The U-14 age group was chosen because $40 \%$ of soccer matches were still played on a dirt field, at the regional championship U-14 (AF Porto, Portugal). The participants' (teams and players) selection was conducted in accordance with the following criteria: 1) teams and players registered at the Porto Football Association championship; 2) teams and players from the same competitive level. All players and their coaches were informed about the research procedures, requirements, benefits and risks, and written informed consent was obtained from parents before the study began. The study protocol followed the guidelines outlined in the Declaration of Helsinki and was approved by the local Ethics Committee.

Measures

The positional data were used to calculate: (1) players' spatial distribution variability, assessed by measuring the entropy of individual spatial distribution maps (Shannon, 1948; Silva et al., 2015). These maps were obtained from discretization of the pitch into sectors of 1 $\mathrm{m}^{2}$, allowing to calculate the amount of time spent in each sector, normalized to total match duration to produce spatial probability distributions. In this way, a normalized value of entropy, ranging from 0 to 1 , was calculated to quantify the uncertainty of locating each player in a specific location of the pitch. A low entropy value (near zero) indicating a sharply peaked distribution, suggests the player's position can be easily predicted. On the other hand, a high entropy value (near 1) corresponds to an uniform distribution and suggests the player exhibits high spatial distribution variability or that its position is highly variable and unpredictable (Silva et al., 2015). Taking into consideration the participant's experience, the entropy was also related with team tactical performance. Thus, teams with players with high entropy values were interpreted as using a game style that promoted positional exchanges between players and more diversified tactical functions. On the other hand, teams with players with low entropy values were interpreted as using a game style based on more consistent displacement and more specific tactical functions; (2) the covered area by players in the pitch surface, assessed by measuring the area of ellipses representative of players' pitch displacement, centred on the average positional coordinates of the players, with axes corresponding to the standard deviation of displacement in the longitudinal and lateral directions of the pitch (Zengyuan et al., 2008). Through elliptic forms we evaluated qualitatively the main directions of the players movements and their distribution and relative positioning on the pitch (Silva et al., 2014b). The ellipse areas were also calculated to provide quantitative information of the space predominantly used by each player during soccer matches.

\section{Design and procedures}

During three weeks, always on Sunday, a 
total of 9 soccer matches were performed and analysed, in the following condition: week (1) -3 matches on artificial turf; week (2) - 3 matches on natural turf; week (3) -3 matches on a dirt field. The teams and players who participated in the study were always the same and all soccer matches were played using 1-4-3-3 tactical structure, the most frequent in Portuguese youth teams (Rebelo et al., 2014). The players were classified according to their playing positional role: 1) central defenders (DC, $n=12) ; 2$ ) centre forwards (CF, $n=6)$; 3 ) central midfielders (CM, $n$ $=18)$; 4) wide midfielders ( $\mathrm{WM}, n=12)$; 5) fullbacks (FB, $n=12)$. The goalkeepers participated in the matches, but were excluded from the analysis. The matches were played according to soccer rules, except match duration (30min, without breaks) and players' substitution (not allowed). The pitch size was adjusted to standardize the measure for all conditions (length: $100 \mathrm{~m}$, width: $64 \mathrm{~m}$ ). Six extra soccer balls were always available near the goalposts and on the side of the pitch for prompt replacement when the ball left the playing area. All matches were proceeded by a planned, standardised warm up of 15 min comprising running activities, smallsided games and stretching. Following this period, the players simulated a match during two periods of $2 \mathrm{~min}$, interspersed by $1 \mathrm{~min}$ of passive recovery. All games were played between 9 and 11 a.m., under similar climatic conditions.

Each player carried a global positioning tracking device (Qstarz, Model: BT-Q1000eX) that recorded his $2 \mathrm{D}$ positional coordinates at a sampling frequency rate of $10 \mathrm{~Hz}$. The GPS device was placed on the upper back of the player (using an appropriate harness). The playing surfaces were calibrated with the coordinates of four GPS devices stationed in each corner for approximately $4 \mathrm{~min}$. The absolute coordinates of each corner were calculated as the median of the recorded time series, providing robust measurements to typical fluctuations of the GPS signals. These absolute positions were also used to define the reference Cartesian coordinate systems for each pitch, with its origin placed at the pitch centre. GPS longitudinal and latitudinal (spherical) coordinates were converted into Euclidean (planar) coordinates with the Haversine formula (Sinnott, 1984). Fluctuations in players positions were reduced using a moving average filter with a time scale of $0.2 \mathrm{~s}$ and data resampling was employed to synchronize the time series of all players within each soccer match (Silva et al., 2014a; Silva et al., 2015). All data were recorded in Microsoft Office Excel 2007 (Microsoft Corporation, USA) and subsequently exported to SPSS Statistics, version 22.0 (SPSS Inc., Chicago, USA). MatLab software (R2014a, Math works Inc., USA) was used to process and analyse the data.

\section{Statistical analysis}

Results are expressed as means \pm standard deviations. A two-way analysis of variance (ANOVA) with repeated measures was employed to evaluate the differences in the described variables between each pitch surface. The Mauchly's test of sphericity was performed on all data to verify any violations of sphericity that were corrected through the Greenhouse-Geisser adjustment (Bathke et al., 2009). Effect sizes were reported as partial eta squared $\left(\eta^{2}\right)$ obtained with the ANOVAs, following Cohen's guidelines (Cohen, 1988): (i) $0.01 \leq \eta^{2}<0.06$ - small effect; (ii) $0.06 \leq \eta^{2}<0.14$ - moderate effect; and (iii) $\eta^{2} \geq 0.14$ - large effect. Post hoc analysis was performed using the Bonferroni adjustment. All statistical analyses were carried out using SPSS Statistical Analysis Software (SPSS Inc., Chicago, USA) version 22.0 for Windows.

\section{Results}

\section{Spatial distribution}

The entropy values were higher on the dirt field compared to the other pitch surfaces (Figure 1). ANOVAs yielded a main effect for pitch surfaces $F(2.110)=9.417 ; p<0.001, \eta^{2}=0.146$;

$=0.977$. Post-hoc analysis revealed significant differences between a dirt field and artificial turf $(p=0.019)$ and natural turf $(p<0.001)$. Between the artificial turf and natural turf no significant differences were found ( $p=0.708$ ).

Figure 2 presents an example of spatial distribution maps of players for each pitch surface, highlighting lower variability in spatial distribution for the natural turf surface than other surfaces.

\section{Relative positioning}

Figure 3 illustrates the ellipse areas, centred on the average of players' positional coordinates, with semi-axes that correspond to the standard deviation of displacement in the longitudinal and lateral directions on each pitch 
surface. The ellipse areas of the artificial turf show less eccentricity and are more overlapping compared to other surfaces.

ANOVAs yielded a significant effect of the pitch surface on the mean area covered by the players; $F(2.110)=3.667, p<0.05, \eta^{2}=0.063 ;=$ 0.664 (Figure 1). Post-hoc analysis showed significant differences between the dirt field and artificial turf ( $p=0.012)$. However, no differences were found between natural turf and the dirt field $(p=0.582)$ nor between natural turf and artificial turf $(p=0.627)$.

\section{Spatial distribution and relative positioning across players' positions}

The differences in spatial distribution and a mean area covered by players across their positional role are presented in Table 1 . Significant differences in ShannEn values were observed across players' positions in all pitch surface conditions; $F(4.55)=13.51 ; p<0.001, \eta^{2}=$ $0.496 ; \quad=1.000$ (Table 1). Specifically, central midfielders presented the greatest ShannEn values compared with other players' positions, while fullbacks showed the lowest values $(p<$ $0.05)$. The differences were most evident on the dirt field.

With regard to the mean area covered, significant differences were observed across players' positions on artificial turf; $F(4.55)=4.465$; $p=0.003$ and the dirt field; $F(4.55)=4.425 ; p=$ 0.004 , respectively. No differences were found on natural turf (Table 1). Central midfielders presented the greatest mean area covered, while fullbacks the lowest $(p<0.05)$.

\section{Discussion}

The aim of this study was to analyze displacement and positioning of players during soccer matches performed on artificial turf, natural turf and a dirt field. For this purpose, variability of the respective spatial distribution was evaluated and the mean area covered by each player was quantified.

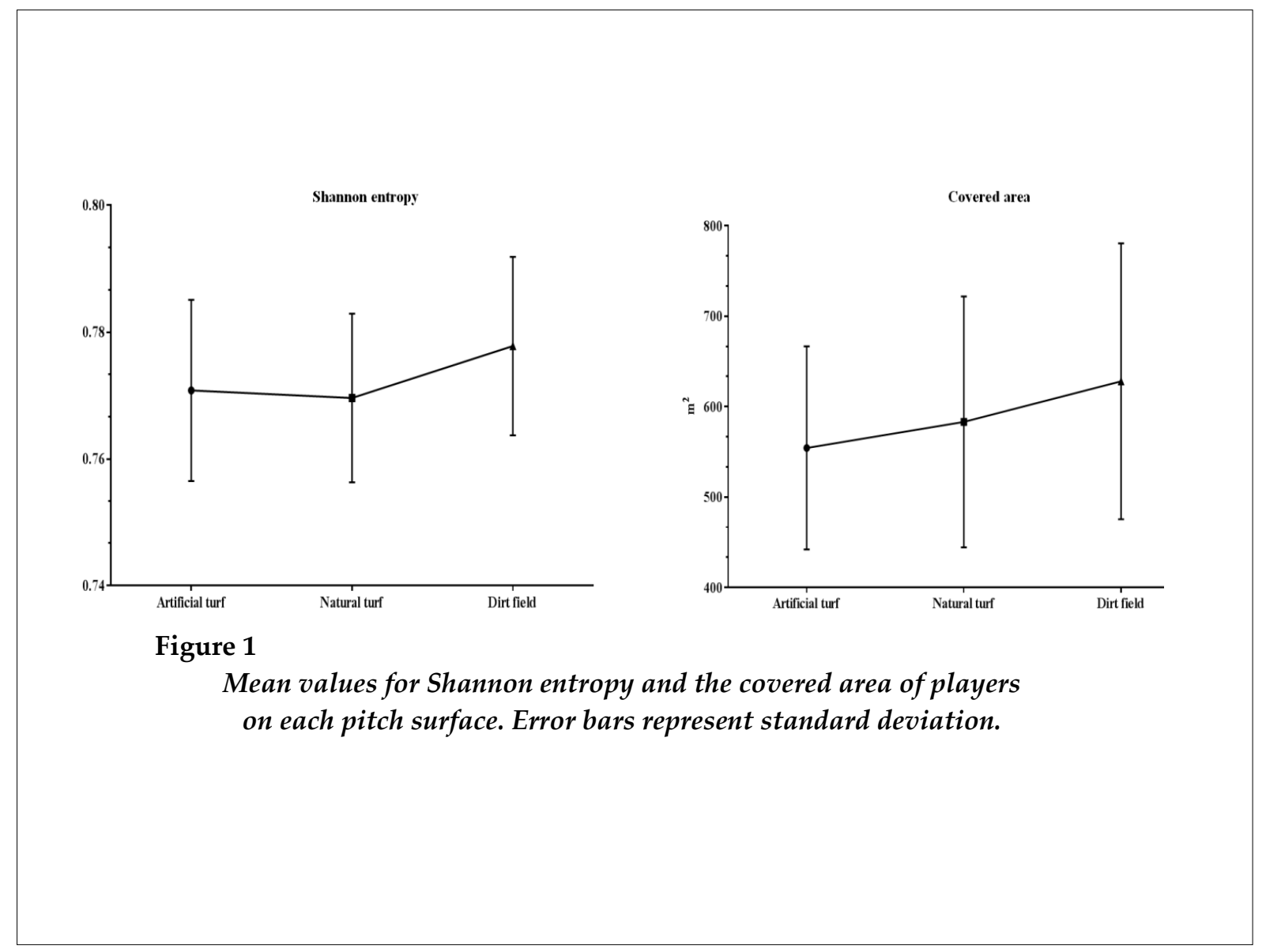


A

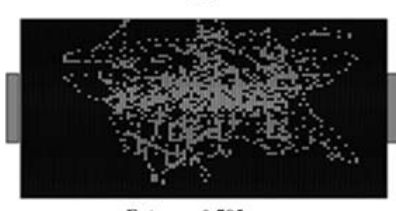

Entropy $=0.785$

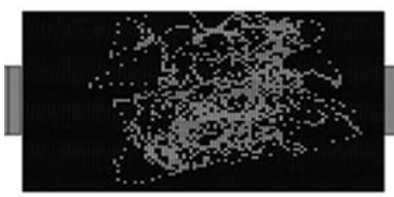

Entropy $=0.785$

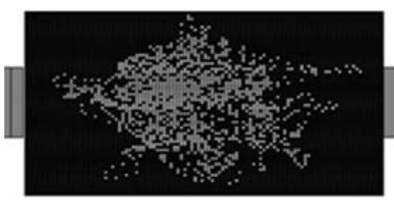

Entropy $=0.783$
B

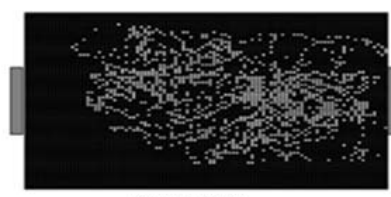

Entropy $=0.784$

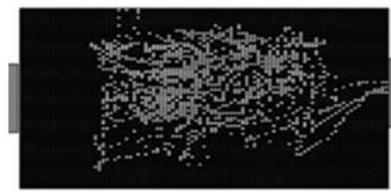

Entropy $=0.785$

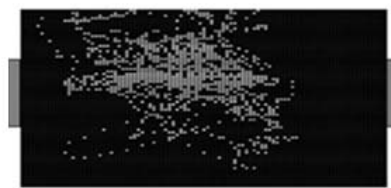

Entropy $=0.757$

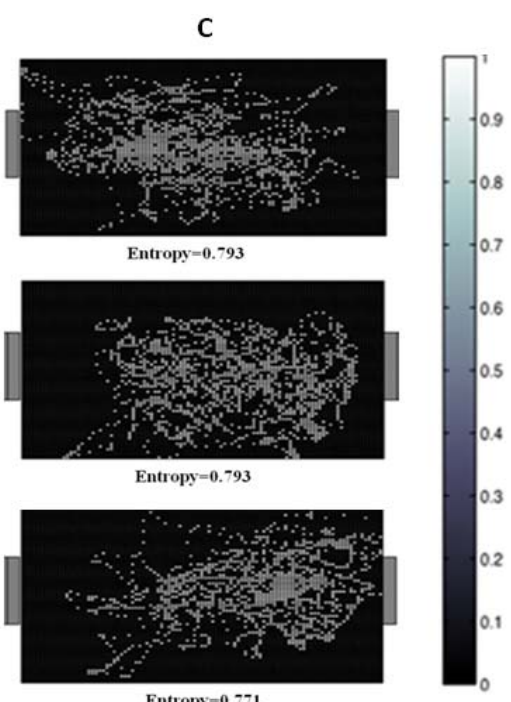

Entropy $=0.771$

Figure 2

Spatial distribution maps of players for each pitch surface condition.

A) artificial turf; B) natural turf; C) dirt field

Note: The values of Shannon entropy presented represents the mean values of players on each pitch surface and soccer match performed.

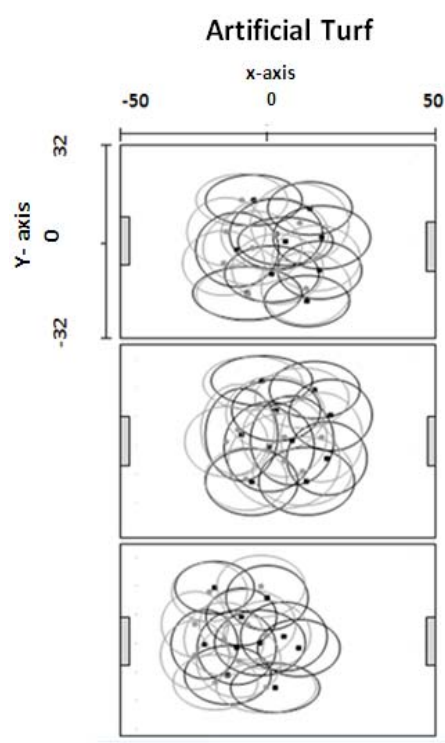

Figure 3

Players' elliptical areas on each surface. Black and grey ellipses depict the players' major displacement of each team, respectively. Lateral (y-axis) and longitudinal

$(x$-axis) axes depict pitch coordinates. 


\begin{tabular}{|c|c|c|c|c|c|c|c|c|c|}
\hline \multicolumn{10}{|c|}{$\begin{array}{c}\text { Table } 1 \\
\text { Entropy values and the mean area covered according to the players' } \\
\text { position on each pitch surface (mean } \pm S D)\end{array}$} \\
\hline Variable & $\begin{array}{l}\text { Pitch } \\
\text { Surfa } \\
\text { ce }\end{array}$ & $\begin{array}{l}\text { All } \\
\text { players } \\
(n=60)\end{array}$ & $\begin{array}{l}\text { Central } \\
\text { defender } \\
(\mathrm{CD}) \\
(n=12)\end{array}$ & $\begin{array}{c}\text { Centre } \\
\text { forwar } \\
\mathrm{d} \\
(\mathrm{CF}) \\
(n=6)\end{array}$ & $\begin{array}{l}\text { Central } \\
\text { midfield } \\
\text { er }(C M) \\
(n=18)\end{array}$ & $\begin{array}{l}\text { Wide } \\
\text { midfielde } \\
\mathrm{r}(\mathrm{WM}) \\
(n=12)\end{array}$ & $\begin{array}{l}\text { Fullback } \\
\text { (FB) } \\
(n=12)\end{array}$ & $p$ & $\begin{array}{c}\text { Post hoc } \\
\text { (Bonferroni) }\end{array}$ \\
\hline \multirow{3}{*}{$\begin{array}{l}\text { Shannon } \\
\text { entropy }\end{array}$} & $\mathrm{AT}$ & $\begin{array}{l}0.771 \\
\pm \\
0.14\end{array}$ & $\begin{array}{l}0.768 \\
\pm \\
0.08\end{array}$ & $\begin{array}{c}0.779 \\
\pm \\
0.07\end{array}$ & $\begin{array}{c}0.782 \\
\pm \\
0.01\end{array}$ & $\begin{array}{c}0.764 \\
\pm \\
0.02\end{array}$ & $\begin{array}{c}0.759 \\
\pm \\
0.011\end{array}$ & $\begin{array}{c}p< \\
0.01\end{array}$ & $\begin{array}{c}\mathrm{CD}<\mathrm{CM}\left({ }^{*}\right) \mathrm{CF} \\
>\mathrm{FB}\left({ }^{*}\right) \mathrm{CM}> \\
\mathrm{WM}\left({ }^{*}\right) \mathrm{CM}> \\
\left.\mathrm{FB}^{(* *}\right)\end{array}$ \\
\hline & NT & $\begin{array}{c}0.769 \\
\pm \\
0.01\end{array}$ & $\begin{array}{c}0.767 \\
\pm \\
0.01\end{array}$ & $\begin{array}{c}0.767 \\
\pm \\
0.01\end{array}$ & $\begin{array}{c}0.781 \\
\pm \\
0.01\end{array}$ & $\begin{array}{c}0.765 \\
\pm \\
0.01\end{array}$ & $\begin{array}{c}0.762 \\
\pm \\
0.02\end{array}$ & $\begin{array}{c}p< \\
0.001\end{array}$ & $\begin{array}{c}\mathrm{CD}<\mathrm{CM}\left({ }^{*}\right) \\
\mathrm{CM}>\mathrm{WM}\left({ }^{*}\right) \\
\mathrm{CM}>\mathrm{FB}\left({ }^{*}\right)\end{array}$ \\
\hline & DF & $\begin{array}{c}0.778 \\
\pm \\
0.01\end{array}$ & $\begin{array}{c}0.771 \\
\pm \\
0.01\end{array}$ & $\begin{array}{c}0.774 \\
\pm \\
0.01\end{array}$ & $\begin{array}{c}0.791 \\
\pm \\
0.01\end{array}$ & $\begin{array}{c}0.776 \\
\pm \\
0.01\end{array}$ & $\begin{array}{c}0.769 \\
\pm \\
0.02\end{array}$ & $\begin{array}{c}p< \\
0.001\end{array}$ & $\begin{array}{c}\left.\mathrm{CD}<\mathrm{CM}^{(* *}\right) \\
\mathrm{CF}<\mathrm{CM}\left({ }^{*}\right) \mathrm{CM} \\
>\mathrm{WM}\left({ }^{*}\right) \mathrm{CM}> \\
\left.\mathrm{FB}^{(* *}\right)\end{array}$ \\
\hline \multirow{3}{*}{$\begin{array}{l}\text { Covered } \\
\text { area }\end{array}$} & AT & $\begin{array}{c}554.4 \\
\pm \\
112.3\end{array}$ & $\begin{array}{c}522.1 \\
\pm \\
67.3\end{array}$ & $\begin{array}{c}578.2 \\
\pm \\
87.9\end{array}$ & $\begin{array}{c}626.6 \\
\pm \\
140.9\end{array}$ & $\begin{array}{c}543.6 \\
\pm \\
92.5\end{array}$ & $\begin{array}{c}477.2 \\
\pm \\
61.4\end{array}$ & $\begin{array}{c}p= \\
0.003\end{array}$ & $\mathrm{FB}<\mathrm{CM}\left({ }^{*}\right)$ \\
\hline & NT & $\begin{array}{c}583.2 \\
\pm \\
138.8\end{array}$ & $\begin{array}{c}545.1 \\
\pm \\
107.9\end{array}$ & $\begin{array}{c}583.5 \\
\pm \\
171.4\end{array}$ & $\begin{array}{c}640.6 \\
\pm \\
138.7\end{array}$ & $\begin{array}{c}598.1 \\
\pm \\
161.9\end{array}$ & $\begin{array}{c}520.3 \\
\pm \\
104.1\end{array}$ & $\begin{array}{c}p= \\
0.157\end{array}$ & \\
\hline & DF & $\begin{array}{c}628.1 \\
\pm \\
152.6\end{array}$ & $\begin{array}{c}554.7 \\
\pm \\
135.7\end{array}$ & $\begin{array}{c}574.1 \\
\pm \\
92.3\end{array}$ & $\begin{array}{c}731.2 \\
\pm \\
160.8\end{array}$ & $\begin{array}{c}642.3 \\
\pm \\
156.9\end{array}$ & $\begin{array}{c}549.8 \\
\pm \\
86.8\end{array}$ & $\begin{array}{c}p= \\
0.004\end{array}$ & $\begin{array}{l}\mathrm{CM}>\mathrm{CD}(*) \\
\mathrm{CM}>\mathrm{FB}\left({ }^{*}\right)\end{array}$ \\
\hline \multicolumn{10}{|c|}{$\begin{array}{l}\text { Note: Significant difference across players' positions; }(p \leq 0.05)^{*} \text {; and }(p \leq 0.001)^{*} \\
\text { Pitch surface conditions. AT: artificial turf; NT: natural turf; DF: dirt field }\end{array}$} \\
\hline
\end{tabular}

\section{Spatial distribution variability}

The major findings were that the action zones of players were more restricted on artificial turf and natural turf than on a dirt field surface, which reveals more uncertainty in the behavioural modes of players on a dirt field. The results showed that players explored more variable areas of the pitch on the dirt field, which can be confirmed by the spatial distribution of players in different pitch conditions (Figure 2). This is probably due to increased irregularity that the dirt field usually presents, reflecting, therefore, more unstable behaviours. Thus, the players' spatial distribution seems to provide relevant information about the tactical roles or style of play for each match-play condition, as observed by Silva et al. (2015).

The Shannon entropy values showed that players' spatial distribution variability was significantly different in the three surfaces, especially between the dirt field and other surfaces. In general, during pitch surface manipulations, the higher spatial distribution variability was verified on the dirt field, which may result from greater flexibility of movement that players perform to adapt to the surface conditions and ball trajectories, probably more unpredictable on this surface. Thus, the greater 
variability observed on the dirt field expresses the continuous effort of the players to adapt to the characteristics of this surface, which seems to induce a greater number of unexpected events and specific restrictions in the game profile. This is non-systematic variability, which reflects unintentional movements or actions that probably were not previously defined. Such characteristics of movement or actions may constraint tactical behaviour of players and teams, contributing, for instance, to inducing undefined tactical functions to players as well as a more individualistic team game profile (Folgado et al., 2014). On the other hand, artificial turf and natural turf reflected less variability, characterized by being under control of players and expressing their intentional and systematic movements or actions. Accordingly, the game profile on these surfaces was more structured from the tactical point of view, where the players demonstrated a more balanced relationship between lateral and longitudinal movements (Silva et al., 2015). In this context, it can be hypothesised that the pitch surface characteristics affect players' behaviour, constraining their variability of movements and actions. In addition, the nature and properties of the surface also seem to influence characteristics of the game (Andersson et al., 2008; Stiles et al., 2009), which was reflected in the trend to a direct and less structured game profile on the dirt field compared to artificial turf and natural turf.

\section{Relative positioning}

Considering the mean area covered by players, our results indicate that the dirt field surface presented a larger mean area than other surfaces, especially in relation to artificial turf. While we are not aware of any comparable data in the literature, it can be hypothesized that the natural turf, but especially dirt field surface, induces an increase in the mean area covered by players. Probably, this trend may result from effects that these surfaces may induce on certain indicators, such as the velocity or trajectory of the ball as well as players' running performance, impairing in this way players' movement on the pitch.

Analyzing the ellipse shapes, it was found that artificial turf condition induced less eccentricity and was more overlapping compared to the natural turf and dirt field (Figure 3), which reflects a more balanced configuration of different sections of the pitch. This elliptical configuration suggests a greater coordination between players, reflecting a more structured and collective game profile (Bartlett et al., 2012). In this context, it seems that artificial turf promotes a tactically more balanced game, expressed in smaller eccentricity of the shapes configuration on this surface, which was revealed by longitudinal and lateral movements with a similar amplitude. This evidence was not that clear on other pitch surfaces, especially on the dirt field, where the longitudinal displacement of players in the pitch was more pronounced. Thus, it can be hypothesised that the dirt field surface induces a game profile dominated by long passes rather than a tactically elaborated game concept, where ball circulation predominates (Silva et al., 2014b; Stiles et al., 2009). This information could be valuable for coaches that intend to improve tactical performance of the players and respective teams.

\section{Spatial distribution and covered area across players' positions}

Since it is well established that players' performance can change as a result of gradual changes in the player's action capabilities or changes in playing conditions (Fajen et al., 2009), we expected differences in spatial distribution and the mean area covered by the players across their playing positions. Our results confirmed that spatial distribution and the covered area were significantly different across players' positions (Table 1). Central midfielders showed the highest variability and mean area covered, especially on the dirt field surface. These findings are in contrast to Moura et al. (2015) who observed that external midfielders and external defenders presented the greatest variability across positions. The participants' characteristics and study design might explain the observed differences (in the aforementioned study national-team players were assessed during the UEFA European Championship). Also, the presented values (Table 1) suggest that central midfielders constitute the positional role with greater variability of movements and, therefore, with greatest influence on the actions of the game, as shown in previous research (Dellal et al., 2012). Moreover, the main role of central midfielders is to control the pitch's centre, which can induce the greatest movement amplitudes in the longitudinal and lateral 
directions compared to the other positional roles (Silva et al., 2014b). On the other hand, fullbacks showed the lowest spatial distribution variability and mean area covered, in all pitch surface conditions. This trend suggests that fullbacks reveal behaviours and movements more predictable than other positional roles, which, according to Moura et al. (2015), could facilitate a precise evaluation of their performance by their opponents. Such as fullbacks, central defenders also presented a smaller mean area covered, especially on the dirt field surface. These indicators seem to confirm that central defenders are the least participatory players during a game. This may result from the inherent specificity of the tactical role, with offensive-defensive actions that may induce a smaller amount of forward, backward, and sideways movement. If the number of tasks to be performed by the players increases, it will induce greater unpredictability to the individual performance of the players as well as greater complexity to the game profile of the team, i.e., it will increase variability. On the other hand, if the number of tasks to be performed by the players decreases, it will induce greater predictability to the individual performance of the players as well as smaller complexity to the game concept of the team, i.e., it will decrease variability. This information can be a key factor to the coaches in order to adapt the training requirements to the characteristics of the players and their positional roles.

\section{Conclusions}

This study concludes that young soccer players perform more unstable and random movements in the dirt field, suggesting that this surface can be used by coaches as a useful tool for training players' technical and tactical skills along their learning pathways. On the other hand, the artificial turf promotes a more structured style of play from a tactical viewpoint, demonstrating that it can be an excellent alternative to the natural turf to perform formal games, which can be used by national governing bodies to implement effective formal soccer activities in their youth development system (Ford et al., 2012). Our findings also showed that there were significant differences across the positional roles of players in the range of movement and displacement, suggesting that coaches should pay attention to the design of their training sessions and to constructing training units according to the requirements and adaptations of the respective positional role. Future studies could identify other specific conditions that may influence players' tactical behaviours, such as the players level (elite and non-elite), different age groups and different team formations (play systems), to provide deeper understanding of the players' actions and tactical relations during games.

\section{Acknowledgements}

We thank all the players and managers of the soccer teams for their collaboration. The authors have no conflict of interest directly relevant to the content of this article. No external financial support was received for this investigation.

\section{References}

Andersson H, Ekblom B, Krustrup P. Elite football on artificial turf versus natural grass: Movement patterns, technical standards, and player impressions. J Sports Sci, 2008; 26(2): 113-122

Bartlett R, Button C, Robins M, Dutt-Mazumder A, Kennedy G. Analysing team coordination patterns from player movement trajectories in soccer: Methodological considerations. Int J Performance Analysis in Sport, 2012; 12(2): 398-424

Bathke AC, Schabenberger O, Tobias RD, Madden LV. Greenhouse-Geisser adjustment and the ANOVAtype statistic: Cousins or twins? American Statistician, 2009; 63(3): 239-246. doi:10.1198/tast.2009.08187

Cohen J. Statistical power analysis for the behavioral sciences (2nd ed.). Hillsdale, NJ: Lawrence Erlbaum Associates; 1998

Couceiro MS, Clemente FM, Martins FML, Tenreiro Machado JA. Dynamical stability and predictability of football players: The study of one match. Entropy, 2014; 16(2): 645-674. doi:10.3390/e16020645 
Coutts AJ, Duffield R. Validity and reliability of GPS devices for measuring movement demands of team sports. J Sci and Med in Sport, 2010; 13(1): 133-135

Cummins C, Orr R, O'Connor H, West, C. Global positioning systems (GPS) and microtechnology sensors in team sports: A systematic review. Sports Med, 2013; 43(10): 1025-1042

Dellal A, Owen A, Wong DP, Krustrup P, van Exsel M, Mallo J. Technical and physical demands of small vs. large sided games in relation to playing position in elite soccer. Hum Mov Sci, 2012; 31(4): 957-969

Fajen B, Riley M, Turvey M. Information, affordances, and the control of action in sport. Int J Sport Psy, 2009; 40(1): 79

Folgado H, Duarte R, Laranjo L, Sampaio J, Fernandes O. (2007). Heart rate and technical responses to variation in pitch dimension and surface in "three-a-side"youth soccer drills. Available at http://hdl.handle.net/10174/2086; accessed on 18.01.2012

Folgado H, Lemmink KA, Frencken W, Sampaio J. Length, width and centroid distance as measures of teams tactical performance in youth football. Eur J Sport Sci, 2014; 14(sup1): S487-S492

Ford PR, Carling C, Garces M, Marques M, Miguel C, Farrant A, Stenling A, Moreno J, Le Gall F, Holmström S, Salmela JH, Williams M. The developmental activities of elite soccer players aged under-16 years from Brazil, England, France, Ghana, Mexico, Portugal and Sweden. J Sports Sci, 2012; 30(15): 1653-1663

Gray AJ, Jenkins D, Andrews MH, Taaffe DR, Glover ML. Validity and reliability of GPS for measuring distance travelled in field-based team sports. J Sports Sci, 2010; 28(12): 1319-1325. doi:10.1080/02640414.2010.504783

Gréhaigne J. Game systems in soccer from the point of view of coverage of space. In Science and Football: Proceedings of the first world congress of science and football, Liverpool; 2011

Gréhaigne J, Godbout P, Zerai Z. How the "rapport de forces" evolves in a soccer match: The dynamics of collective decisions in a complex system. Revista Psi del Deporte, 2011; 20(2): 747-765

Gréhaigne J, Mahut B, Fernandez A. Qualitative observation tools to analyse soccer. Int J Perf Analysis in Sport, 2001; 1(1): 52-61

Impellizzeri FM, Marcora SM. Test validation in sport physiology: Lessons learned from clinimetrics. Int J Sports Physiology and Performance, 2009; 4(2): 269-277

Jones S, Drust B. Physiological and technical demands of $4 \mathrm{v} 4$ and $8 \mathrm{v} 8$ games in elite youth soccer players. Kinesiology, 2007; 39(2): 150-156

Moura F, Santana J, Vieira N, Santiago P, Cunha S. Analysis of soccer players' positional variability during the 2012 UEFA European championship: A case study. J Hum Kinet, 2015; 47(1): 225-236

Rebelo A, Brito J, Seabra A, Oliveira J, Krustrup P. Physical match performance of youth football players in relation to physical capacity. Eur J Sport Sci, 2014; 14(sup1): S148-S156

Santos R, Dias C, Garganta J, Costa I. Does playing surface influence the tactical performance of soccer players? Rev da Educação Física/UEM, 2013; 24(2): 247-252

Shannon CE. A mathematical theory of communication. The Bell System Tec J, 1948; 27: 623

Silva P, Aguiar P, Duarte R, Davids K, Araújo D, Garganta J. Effects of pitch size and skill level on tactical behaviours of association football players during small-sided and conditioned games. Int J Sports Sci E Coaching, 2014a; 9(5): 993-1006

Silva P, Esteves P, Correia V, Davids K, Araújo D, Garganta J. Effects of manipulations of player numbers vs. field dimensions on inter-individual coordination during small-sided games in youth football. Int $J$ Performance Analysis in Sport, 2015; 15(2): 641-659

Silva P, Travassos B, Vilar L, Aguiar P, Davids K, Araújo D, Garganta J. Numerical relations and skill level constrain co-adaptive behaviors of agents in sports teams. PloS One, 2014b; 9(9): e107112 
Sinnott RW. Sky and telescope. Virtues of the Haversine, 1984; 68(2): 159

Stiles VH, James IT, Dixon SJ, Guisasola IN. Natural turf surfaces: The case for continued research. Sports Med, 2009; 39(1): 65-84

Stølen T, Chamari K, Castagna C, Wisløff U. Physiology of soccer. Sports Med, 2005; 35(6): 501-536

Yue Z, Broich H, Seifriz F, Mester J. Mathematical analysis of a soccer game. Part I: Individual and collective behaviors. Studies in Applied Mathematics, 2008; 121(3): 223-243

Zengyuan Y, Broich H, Seifriz F, Mester J. Mathematical analysis of a soccer game. Part I: Individual and collective behaviors. Studies in Applied Mathematics, 2008; 121(3): 223-243. doi:10.1111/j.14679590.2008.00413.x

\section{Corresponding author:}

\section{Ângelo Brito}

1CIFI2D - Centre for Research, Education, Innovation and Intervention in Sport,

Faculty of Sport, University of Porto, Porto, Portugal

Phone: 00351914165023

E-mail: amiguelpbrito@gmail.com 